\title{
Vertical Integration and Distance to Frontier
}

\section{Citation}

Acemoglu, Daron, Philippe Aghion, and Fabrizio Zilibotti. 2003. Vertical integration and distance to frontier. Journal of the European Economic Association 1, no. 2-3: 630-638.

\section{Published Version}

http://dx.doi.org/10.1162/154247603322391260

\section{Permanent link}

http://nrs.harvard.edu/urn-3:HUL.InstRepos:4481512

\section{Terms of Use}

This article was downloaded from Harvard University's DASH repository, and is made available under the terms and conditions applicable to Other Posted Material, as set forth at http:// nrs.harvard.edu/urn-3:HUL.InstRepos:dash.current.terms-of-use\#LAA

\section{Share Your Story}

The Harvard community has made this article openly available.

Please share how this access benefits you. Submit a story.

\section{Accessibility}




\title{
VERTICAL INTEGRATION AND DISTANCE TO FRONTIER
}

Daron Acemoglu

Massachusetts Institute of Technology

Philippe Aghion

Harvard University and University

College London

\section{Fabrizio Zilibotti}

University College London

\begin{abstract}
We construct a model where the equilibrium organization of firms changes as an economy approaches the world technology frontier. In vertically integrated firms, owners (managers) have to spend time both on production and innovation activities, and this creates managerial overload, and discourages innovation. Outsourcing of some production activities mitigates the managerial overload, but creates a holdup problem, causing some of the rents of the owners to be dissipated to the supplier. Far from the technology frontier, imitation activities are more important, and vertical integration is preferred. Closer to the frontier, the value of innovation increases, encouraging outsourcing. (JEL: L22, O31, O33, O38, O40, L16)
\end{abstract}

\section{Introduction}

A view dating back at least to Gerschenkron (1962) sees considerable differences in the organization of firms and the economy in general between technologically advanced societies and those that are technological followers. In economies that are technologically relatively backward, there are more long-term relationships between firms and banks, larger, perhaps more vertically integrated, firms, less competition, greater state intervention, and generally more "rigid" institutions.

In Acemoglu, Aghion, and Zilibotti (2002) (henceforth AAZ) we formalize this notion, and build on it to analyze a range of issues related to technological progress and economic growth. In this paper, we study the relationship between vertical integration and technological convergence. Outsourcing avoids managerial overload and increases innovation-related activities (as in Aghion and Tirole 1997). Vertical integration, on the other hand, avoids the holdup problems and the rent sharing associated with outsourcing (as in Grossman and Hart 1986). Building on the same ideas as in AAZ, we argue that innovation activities

Acknowledgments: We are grateful to Pol Antras and the participants in the European Economic Association conference in Venice for useful comments.

E-mail addresses: Acemoglu: daron@mit.edu; Aghion: p_aghion@harvard.edu; Zilibotti: fabrizio_zilibotti@iies.su.se 
become more important as the economy approaches the world technology frontier. Therefore, at some point it becomes worthwhile to incur the costs of sharing the rents with suppliers, in order to benefit from greater innovation by outsourcing some of the production activities.

The paper is organized as follows. Section 2 presents the macroeconomic part of the model and derives the dynamic equation for aggregate productivity. Section 3.1 derives the equilibrium investments in scale and innovation under vertical integration and nonintegration (outsourcing). Section 3.2 analyzes how firm owners' decisions whether or not to vertically integrate depends upon the country's distance to the technological frontier. Section 3.3 shows how persistent integration may lead to nonconvergence traps.

\section{Basic Setup}

\subsection{Agents and Production}

The economy is populated by a continuum of non-overlapping generations of one-period lived agents. Each generation consists of a mass 1 of "capitalists" who hold initial property rights over "production sites," and a mass $1+L$ of workers that can also be employed as managers. Each worker is endowed with one unit of labor that she supplies inelastically with no disutility. All individuals are risk neutral.

There is a unique final good that serves as numeraire and is produced competitively using labor and a continuum of intermediate inputs according to:

$$
y_{t}=\frac{1}{\alpha} L^{1-\alpha}\left[\int_{0}^{1}\left(s_{t}(\nu) A_{t}(\nu)\right)^{1-\alpha} x_{t}(\nu)^{\alpha} d \nu\right],
$$

where $s_{t}(v) A_{t}(\nu)$ is the productivity in sector $\nu$ at time $t, x_{t}(\nu)$ is the flow of intermediate good $\nu$ used in final good production again at time $t$, and $\alpha \in[0$, 1], $s_{t}(v)$ will be the component of productivity coming from firm-specific investments, and $A_{t}(\nu)$ is the state of technology in this sector, determined by imitation and innovation activities.

In each intermediate sector $\nu$, one intermediate producer can produce 1 unit of intermediate good with leading-edge productivity $A_{t}(\nu)$, using 1 unit of final good as capital. Firm-specific investments and productivity improvements are decided at the beginning of the period. Ex post each intermediate good producer faces a competitive fringe of imitators that forces her to charge a limit price: $p_{t}(\nu)=\chi$. Demand for each intermediate is given from (1) as $x_{t}(v)=$ $\left(p_{t}(\nu)\right)^{-1 /(1-\alpha)} s_{t}(v) A_{t}(\nu) L$. Using the limit price, equilibrium monopoly profits are therefore obtained as:

$$
\pi_{t}(\nu)=\delta s_{t}(\nu) A_{t}(\nu) L
$$


where $\delta \equiv(\chi-1) \chi^{-(1 /(1-\alpha))}$ is a measure of the degree of competition in the economy, and is monotonically increasing in $\chi$. When $\chi$, or equivalently $\delta$, is high, which in turn may be due to technological reasons or to government regulation, there is less competitive pressure, and prices and monopoly profits are higher.

Now define

$$
A_{t} \equiv \int_{0}^{1} A_{t}(\nu) d \nu
$$

as the average productivity in the country at date $t, \bar{A}_{t}$ the productivity at the world frontier (with all countries having a state of technology $A_{t} \leq \bar{A}_{t}$ ), and $a_{t}=$ $A_{t} / \bar{A}_{t}$ as an (inverse) measure of the country's distance to the technological frontier.

\subsection{Productivity Growth}

Before production takes place at any date, intermediate firms can increase productivity, either by imitating frontier technologies or by innovating upon existing technologies in the country. Imitation is automatic, but innovation requires investments and skills on the part of entrepreneurs/managers, and the success of innovation will vary between firms and over time. More specifically, we assume:

$$
A_{t}(\nu)=\eta \bar{A}_{t-1}+\gamma_{t}(\nu) A_{t-1},
$$

and that

$$
\gamma_{t}(\nu)=\underline{\gamma}+x_{t}(v)
$$

In this equation, we can interpret $x_{t}(v)$ as the probability that an innovation in sector $v$ at time $t$ is successful. If so, there is innovation in the amount $1+\gamma$. Otherwise, there is a smaller innovation, of size $\gamma$. These innovations build on the knowledge stock of the country, thus they multiply $A_{t-1}$. The first term in (4), on the other hand, reflects imitation from the world technology frontier, hence the term $\bar{A}_{t-1}$.

In equilibrium, all intermediate firms in the same country will choose the same innovative intensity $x_{t}(\nu)=x$. Then, dividing both sides of the above equation by $\bar{A}_{t-1}$, and integrating over $\nu$, we obtain a simple linear equation describing how the state variable $a_{t}=A_{t} / \bar{A}_{t}$ evolves over time, namely:

$$
a_{t}=\frac{1}{1+g}\left(\eta+(\underline{\gamma}+x) a_{t-1}\right)
$$

where $g$ is the growth rate of world technology frontier. ${ }^{1}$

Equation (6) is a simpler version of the productivity growth equation in

1. That the firm-specific investment, $s$, does not contribute to technological progress is inessential for the results. 
AAZ. The basic analysis in AAZ boiled down to comparing various equilibrium organizational choices, affecting the $\eta$ and $x$ terms in (6). Relying on experience increases $\eta$ at the expense of $x$, whereas choosing the innovation-based strategy increases $x$ at the expense of $\eta$. As the economy approaches the world technology frontier, $a$, increases, and selection and innovation become more important. This in turn tilts the balance towards organizational choices that favor selection and innovation. In AAZ, the major decision was whether or not to terminate less successful firms and managers. Here we will look at a complementary decision, that of whether to vertically integrate certain production activities or to outsource them (and in addition, the vertical integration decision here will only affect $x$ and not $\eta$, but see footnote 5).

\section{Distance to Frontier, Vertical Integration, and Convergence}

\subsection{A Simple Model of Vertical Integration Versus Outsourcing}

We now analyze the vertical integration decision of (intermediate sector) firms. These firms (or their owners/the capitalists) can either choose a "vertically integrated" structure, in which they carry out both the production and innovation activities. Alternatively, they can contract out either part of the production activities or innovation activities. Here, because of page limits, we focus only on the case of outsourcing production activities. The basic idea is that investment in the scale of production and innovation both require effort, and perhaps more important time and focus. In the vertically integrated structure, this creates managerial overload. Outsourcing mitigates the managerial overload, but at the same time, it creates a holdup problem: ${ }^{2}$ a new agent is brought in, who will share some of the rents with the owner, thereby reducing the owner's income for given effort, and via this channel, also his incentives to invest.

We model managerial overload by introducing a convex cost of effort; the more effort the manager (or the owner) exerts, the higher is the marginal cost of further effort. More formally, consider the following cost function for effort in the case of vertically-integrated firm:

$$
C_{t}(s, x)=\left\{\begin{array}{l}
k \bar{A}_{t-1} \text { if } s+x \leq T \\
\infty \text { otherwise }
\end{array} .\right.
$$

This cost function specifies that there is a constant fixed cost $k \bar{A}_{t-1}$ (which grows with the state the world technology to ensure balanced growth), and there is 0 marginal cost of effort until $s+x$ reaches $T$, and thereafter, the marginal cost is infinite. Hence, we have an L-shaped - thus extremely convex-marginal

2. Following Grossman and Hart (1986) and the incomplete contracts literature, we assume that no ex ante contract can induce an enforceable division of surplus; sharing of profits must rely entirely upon ex post bargaining. In addition, here we do not consider the case where the owner does not outsource, but hires the supplier as an employee. 
cost curve. The intuitive motivation for this function is that the manager (owner) has a total available time of $T$ which can be spent on production or innovation activities.

We assume that

$$
\eta+\underline{\gamma} \geq T>\underline{\gamma}
$$

The first part of the assumption ensures that the owner has "scarce" time, so that the trade-offs emphasized here are more interesting. The second part is important in making sure that there will be sufficient innovation from devoting time to innovation-type activities, for example by outsourcing.

The maximization problem of the owners of integrated firms is straightforward: choose $(s, x)$ to maximize

$$
U_{t}(\nu)=\delta s_{t}(\nu) A_{t}(\nu) L-C_{t}(s, x)=\delta L s(\eta+(\underline{\gamma}+x) a) \bar{A}_{t-1}-C_{t}(s, x),
$$

where the second equality makes use of the fact that all firms will choose the same $x$ and $s$, and substitutes for $A_{t}(\nu)$ using the definition for $a$ and (4).

Assumption (A1), i.e., the scarcity of managerial time, then immediately implies that the optimum $x$ must be equal to zero. ${ }^{3}$ In other words, in the vertically integrated firm, effort overload discourages innovation. The optimal scale of production is then simply: $s=T$. This, in turn, yields an equilibrium level of utility for the owner equal to:

$$
U_{t}^{V I}=u^{V I}(a) \bar{A}_{t-1}=(\delta L T(\eta+\underline{\gamma a})-k) \bar{A}_{t-1} .
$$

Now consider the case where production activities are outsourced to an independent supplier (we refer to this as the nonintegration case). The supplier's cost function is

$$
C^{s}(s)=\left\{\begin{array}{l}
\beta k \bar{A}_{t-1} \text { if } s \leq T \\
\infty \text { otherwise }
\end{array} .\right.
$$

In other words, the supplier also has total time $T$, which he simply allocates to productive activities, and incurs a fixed cost $\beta k \bar{A}_{t-1}$, which is a fraction of the fixed cost of production incurred by the vertically integrated firm. Once these production activities are outsourced, the cost function of the owner is:

$$
C_{t}^{x}(x)=\left\{\begin{array}{l}
\phi k \bar{A}_{t-1} \text { if } x \leq T \\
\infty \text { otherwise }
\end{array} .\right.
$$

Therefore, the owner can now allocate all her time to innovation activities, and incurs a fixed cost of production $\phi k \bar{A}_{t-1}$. We assume that $\phi \geq 1 / 2$, so the owner incurs a fixed cost at least half as large the fixed cost in the vertical-integrated case (this assumption simplifies some of the comparisons below, and is not

3. The first-order condition for an interior solution yields: $s=(\eta+\gamma a+T a) / 2 a$. A sufficient condition for $s \geq T$, and hence for $x=0$, is $\eta+\underline{\gamma} \geq T$, which is ensured by assumption (A1). 
essential). We also assume that suppliers can still work as workers, so even in the case with outsourcing, the total labor force working in the intermediate sector is equal to $L$.

Following Grossman and Hart (1986) and the incomplete contracts literature, we assume that scale and productivity decisions are ex post unverifiable by third parties and therefore cannot be contracted upon ex ante. Thus the owner and the supplier must rely on ex post bargaining to determine how profits will be shared between them. This creates a standard holdup problem: ex post some of the rents have to be shared with the supplier. To simplify the discussion, we assume that both the owner and the supplier have an outside option equal to zero (i.e., once productive activities are outsourced, and investment decisions are taken, the owner can no longer carry out productive activities if there is disagreement). In addition, we assume that the surplus is large enough to cover the fixed cost for the supplier. Assuming equal bargaining power between the owner and the supplier over the ex post surplus, each party obtains $1 / 2$ of the ex post surplus from the relationship, namely:

$$
1 / 2 \delta L s(\eta+(\underline{\gamma}+x) a) \bar{A}_{t-1} .
$$

Then, for given scale $s$, the firm will choose her innovation intensity $x$ to maximize its net return $1 / 2 \delta L s(\eta+(\underline{\gamma}+x) a) \bar{A}_{t-1}-C_{t}^{x}(x)$, and the supplier chooses the scale of production, $s$, to maximize $1 / 2 \delta L s(\eta+(\gamma+x) a) \bar{A}_{t-1}-$ $C_{t}^{s}(s)$ taking the innovation intensity, $x$, as given. In equilibrium, we have:

$$
s^{N I}(a)=T \quad \text { and } \quad x^{N I}(a)=T .
$$

Notice that in this case, despite the holdup problems, there is no underinvestment because the marginal cost of investment is L-shaped. In a more general model, underinvestment would occur and also discourage outsourcing. Given (8), the equilibrium ex ante utility for the firm is equal to:

$$
U_{t}^{N I}=u^{N I}(a) \bar{A}_{t-1}=1 / 2 \delta L T(\eta+\underline{\gamma} a+T a)-\phi k \bar{A}_{t-1} .
$$

Assumption (A1) immediately implies that:

$$
\frac{d u^{N I}}{d a}>\frac{d u^{V I}}{d a} .
$$

That is, the larger $a$, i.e., the closer the country is to the technological frontier, the higher the value of innovating and therefore the higher the private benefit of outsourcing. Intuitively, outsourcing becomes privately more costly for the owner as $a$ increases, since greater $a$ implies greater output, which is being shared with the supplier. On the other hand, as $a$ increases, innovation becomes more important, and the value of outsourcing increases. Assumption (A1) ensures that the second effects dominates the first. 


\subsection{Distance to Frontier and Vertical Integration}

We now determine the equilibrium integration decision as a function of the country's distance to the technological frontier (measured by $a$ ). The owners (capitalists) decide whether to remain integrated or outsource production activities. Therefore, to determine the equilibrium organizational form we need to compare $u^{V I}(a)$ given by (7) to $u^{N I}(a)$ given in (9). ${ }^{4}$

First, suppose that $a=0$, then:

$$
u^{N I}(0)=\frac{\delta L T}{2} \eta-\phi k<u^{V I}(0)=\delta L T \eta-k
$$

(recall that $\phi \geq 1 / 2$ ). Thus in economies far away from the world technology frontier, owners prefer to remain vertically integrated: innovation is relatively unimportant compared to imitation in these economies, so outsourcing has little benefits, and high private costs because of the holdup problem. This result holds despite the fact that from a technological point of view, outsourcing is superior to vertical integration: there is no opportunity cost for the supplier (as he still works in production), and there can be greater investments in innovation. Nevertheless, from the owner's point of view, outsourcing has private costs, since the supplier shares some of the rents.

Setting $u^{V I}\left(a^{v}\right)=u^{N I}\left(a^{v}\right)$ from (7) and (9), yields the critical threshold $a^{v} \equiv$ $(\eta-(1-\phi) k / \delta L) /(T-\gamma)$. For all $a<a^{v}$, equilibrium organizational form is vertical integration, and for $a>a^{v}$, there will be outsourcing. The threshold $a^{v}$ is typically less than 1 , so that there will be a switch to outsourcing before reaching the technology frontier. Notice that $a^{v}$ less than 1 is more likely when the fixed production cost $k$ is high, competition is high (i.e., $\delta$ is small), or a $\eta$ is small. More generally, straightforward differentiation shows that $\partial a^{\nu} / \partial \delta>0$ and $\partial a^{v} / \partial \eta \geq 0$, thus vertical integration is more likely in less competitive environments and in sectors where imitation is relatively more important. A less competitive environment creates greater rents, increasing the private costs of rent-sharing resulting from outsourcing. Also when imitation is more important, the innovation benefits of outsourcing are less pronounced relative to the rent sharing costs.

\subsection{Vertical Integration, Growth, and Nonconvergence Traps}

So far we have discussed the effect of the state of technology, and the growth process, on equilibrium organizational forms. Next we analyze the effects of organizational forms, in particular of integration/outsourcing decisions, on the

4. Because production activities are outsourced to suppliers who have no wealth, contracts requiring upfront payments from suppliers to owners are not possible. Contracts where potential suppliers promise ex post payments are ruled out by our incomplete contracts assumption. 
equilibrium growth rate. Consider first an economy with $a_{t}<a^{v}$, where equilibrium organizational form is vertical integration. Then, using equation (4), we can characterize equilibrium productivity growth as:

$$
a_{t+1}=\frac{\eta+\underline{\gamma} a_{t}}{1+g} .
$$

In contrast, in a country with $a_{t}>a^{v}$, owners will outsource production activities, so innovations take place at the rate $\gamma+x^{N I}(a)=\underline{\gamma}+T$. As a result, the law of motion of productivity relative to the frontier is:

$$
\left.a_{t+1}=\frac{1}{1+g}(\eta+(\underline{\gamma}+T)) a_{t}\right) .
$$

Comparing (11) and (12), we see that the economy with outsourcing always grows faster. ${ }^{5}$ This reflects the fact that from a technological point of view, outsourcing is superior, and in equilibrium vertical integration emerges because owners do not want to share the rents with suppliers.

Near the frontier, the maximum growth rate of the economy must be the same as that of the frontier, thus we must also have

$$
\eta+\underline{\gamma}+T=1+g \text {. }
$$

Given this condition, equation (12) implies that an economy with outsourcing always converges towards the world technology frontier, i.e., $(\underline{\gamma}+T) /(1+g)<$ 1. An economy with vertically integrated firms, on the other hand, not only grows at a slower rate than an identical economy with outsourcing, but may also stop converging towards the world technology frontier. To analyze this, first observe that (11) has a fixed point at: $a_{\text {trap }}=\eta /(1+\mathrm{g}-\gamma)<1$. That $\eta /(1+$ $g-\gamma)<1$ immediately follows from (A2). When $a_{t}=a_{\text {trap }}$, an economy with vertical integration stops growing. Therefore, a vertically integrated economy will be stuck in a nonconvergence trap at $a_{\text {trap }}$. This does not, however, establish that an equilibrium with a nonconvergence trap exists. It might indeed be the case that an economy switches out of vertical integration before $a_{\text {trap }}$. Therefore, the condition for an equilibrium nonconvergence trap is that $a_{\text {trap }}<a^{v}$.

When $a_{\text {trap }}<a^{v}$, economies that start with $a_{0}<a^{v}$ will always stay with vertically integrated firms, and never converge to the technology level of the world frontier, whereas economies with $a_{0}>a^{v}$ grow faster and converge the world technology frontier. Since $a^{v}$ is increasing in $\delta$, such traps are more likely in less competitive economies (e.g., in economies where government policy discourages entry). Conversely, in economies with $a_{\text {trap }}<a^{v}$, government

5. It is straightforward to generalize this model, so that vertically integrated firms are more successful in imitation, i.e., they have $\eta^{V I}>\eta^{N I}$. In this case, somewhat more reminiscent to AAZ, at the early stages of development, an economy with vertical integration will grow faster than an economy with outsourcing, while closer to the frontier, outsourcing will produce faster growth. 
policy, for example by increasing competition, i.e., reducing $\delta$, may prevent nonconvergence traps.

\section{References}

Acemoglu, Daron, Philippe Aghion, and Fabrizio Zilibotti (2002). "Distance to Frontier, Selection, and Economic Growth.” NBER Working Paper No. 9066.

Aghion, Philippe and Jean Tirole (1997). "Formal and Real Authority in Organizations." Journal of Political Economy, 105, pp. 1-29.

Gerschenkron, Alexander (1962). Economic Backwardness in Historical Perspective. Cambridge, Massachusetts: Harvard University Press.

Grossman, Sanford and Oliver Hart (1986). "The Costs and Benefits of Ownership: A Theory of Vertical and Lateral Integration.” Journal of Political Economy, 94, pp. 691-719. 